\title{
ONZE DE SETEMBRO: RELEVÂNCIA DA COOPERAÇÃO JUDICIÁRIA INTERNACIONAL.
}

\author{
Rodrigo Elian Sanchez \\ Graduado pela Faculdade de Direito da Universidade de \\ São Paulo. Graduado em Relações Internacionais pela \\ Pontifícia Universidade Católica de São Paulo.
}

\begin{abstract}
Resumo:
Em um contexto cada vez mais complexo e internacionalizado, as ameaças também se propagam de forma difusa, aproveitando-se das novas possibilidades de ação que a globalização traz à tona, ameaças estas simbolizadas pelo atentado terrorista de 11 de setembro de 2001, contra o WTC e o Pentágono. Apenas a coordenação dos esforços dos Estados pode garantir a realização de um mundo dividido em unidades políticas soberanas. Pois se as fronteiras como expressão da soberania forem utilizadas como forma de evasão à lei, a própria legitimidade dos Estados estará comprometida na medida em que a legitimidade caminha de mãos dadas com a eficácia. Diante desses desafios, de um mundo cada vez mais interligado, destaca-se a importância da cooperação judiciária internacional como instrumento de política pública.
\end{abstract}

Abstract:

In an increasingly complex and internationalized reality, the threats are fostering in a diffuse fashions, taking advantage of the new possibilities of action that the globalization creates; treats that could be symbolized by the terrorist attacks of September, 11th, 2001, against WTC and Pentagon. Only the coordination of the efforts of estates could guarantee a world divided in sovereign political unites. If the frontiers, as an expression of the notion of sovereignty, would be used to escape of the rule of law, the legitimacy of the states would be jeopardized; since legitimacy is the other face of efficacy. In the presence of these challenges, of an inter-linked world, turn up the importance of the international judicial co-operation, as an instrument of public policy.

Unitermos: globalização; ameaças difusas; cooperação judiciária internacional.

Após os atentados terroristas de 11 de setembro, 2001, contra o Pentágono e o WTC, muitos foram os debates acerca das conseqüências deste fato às relações internacionais. Não raros foram os que anunciaram ser este episódio o detonador de nova ordem internacional; ocorreria uma redefinição das políticas em face de uma nova realidade que surgia. Poucos foram os que notaram que a realidade do 11 de setembro não é uma novidade, mas, sim, já estava presente antes mesmo dos ataques supostamente arquitetados pela "al-Qaeda" $O$ ataque no máximo iluminou esta 
realidade, possibilitando um olhar mais preciso. Nada que um historiador, como Eric Hobsbawm, não houvesse notado e reafirmado em recente artigo intitulado "A Epidemia da Guerra"'

1. "É um tema a ser debatido o quanto as ações em que as Forças Armadas norteamericanas têm estado envolvidas desde o fim da Guerra Fria em várias partes do globo que constituem uma cóntinuação da era de guerra mundial. Não pode haver dúvida, no entanto, de que os anos 90 foram recheados de conflitos militares formais e informais na Europa, na África e na Ásia Ocidental e na Central. O inundo como um todo não tem estado em paz desde 1914 e não está em paz agora. Apesar disso, o século não pode ser tratado cono um bloco único, seja cronológica, seja geograficamente. Cronologicamente, ele se distribui èn três periodos: a era de guerras mundiais centrada na Alemanha (1914 a 1945), a era de confronto entre as duas superpotências (1945 a 1989) e a era desde o fim do sistema de poder internacional clássico. Eu chamarei esses periodos de 1, 2 e 3. Geograficamente, o impacto das operações militares tem sido desigual. Com uma exceção (a Guerra do Chaco, que opôs Paraguai e Bolivia entre 1932 e 1935 pela posse de campos petroliferos no sopé dos Andes), não houve guerras entre Estados significantes (em oposição a guerras civis) no hemisfério Ocidental (as Américas) no ültimo século. Operações militares inimigas quase não tocaram esses territórios: dai o choque com os ataques ao World Trade Center e ao Pentágono em II de setembro. Desde 1945 as guerras entre Estados também desapareceram da Europa, que tinha sido até então o principal campo de batalha. Apesar de no periodo 3 a guerra ter retornado ao Sudeste da Europa, parece bastante improvável que ocorra no resto do continente. Em contrapartida, durante o periodo 2, guerras entre Estados, não necessariamente desconectadas do confronto global, permaneceram endêmicas ao Oriente Médio e ao Sul da Ásia, e guerras maiores diretamente resultantes do confronto global aconteceram no Leste e no Sudeste da Ásia (Coréia, Indochina). Ao mesmo tempo, áreas como a África subsaariana, que haviam sido comparativamente não afetadas pela guerra no período I (com exceção da Etiópia, sujeita a uma conquista colonial atrasada por parte da ltália em 1935-36), vieram a ser palco de conflitos armados no periodo 2 e testemunharam enormes cenas de massacre e sofrimento no periodo 3. Outras duas características da guerra no século 20 se destacam, a primeira menos obviamente do que a segunda. No início do século 21 nos encontramos em um mundo em que operações armadas não mais estāo essencialmente nas māos de governos ou de seus agentes autorizados e no qual os partidos em disputa não têm características, status ou objetivos comuns, exceto a disposição para usar a violência. Guerras entre Estados dominaram tanto a imagem da guerra durante os períodos l e 2 que guerras civis ou outros conflitos armados dentro dos territórios de Estados ou impérios existentes foran de alguma forma obscurecidos. Mesmo guerras civis no território russo após a Revolução de Outubro, em 1917, e aquelas que ocorreram após o colapso do Império chinês poderiam ser encaixadas na moldura dos conflitos internacionais, na medida em que foram inseparáveis deles. Por outro lado, a América Latina pode não ter visto Exércitos cruzando fronteiras de Estados no século 20, mas foi cenário de grandes conflitos civis: no México depois de 1911, por exemplo, na Colômbia desde 1948 e em vários países da América Central durante o periodo 2. Geralmente não se reconhece que o número de guerras internacionais declinou de forma razoavelmente contínua desde meados dos anos 60 , quando conflitos internos se tornaram mais comuns do que aqueles disputados entre Estados. O número de conflitos dentro de fronteiras nacionais continuou a subir de maneira ingreme até se nivelar nos anos 90. Mais 
Da mesma maneira, Fred Halliday, conceituado internacionalista, não caiu na falácia da dita "nova realidade internacional" e de forma clara expõe tal compreensão da realidade mundial em um artigo, publicado recentemente no periódico "The Observer" intitulado "New world, but the same old disorder" O artigo mesmo sendo breve, o que não poderia ser diferente pois veiculado em periódico, traz interessantes reflexões sobre o atentado e os desafios, por ele aclarados a serem enfrentados pelos policy-makers, e por que não pelos Estados Nacionais.

Diante desta realidade complexa, que o II de setembro desnudou, estabelecem-se três desafios que deverão ser enfrentados. O primeiro seria o reforço da dimensão da segurança na globalização. Globalização não pode ser vista apenas em termos de comércio, turismo, investimento e comunicação. Necessita da dimensão da segurança, responsabilidade de todos Estados. Segurança esta que deve ser tanto efetiva quanto democrática, sob o manto da legalidade. O segundo desafio seria colocar a cooperação internacional não apenas em termos de força, mas também em termos políticos. Ou seja, cooperação visando a uma melhor governança internacional, já que o atual sistema de governança é muito fracionado e inadequado. Cooperação esta que lide com questões como migração, comércio internacional e a crescente desigualdade global. O terceiro desafio seria o apelo à comunidade, expressado através da idéia de choque de civilizações. Entendimento que, sob a aparência de explicar o mundo atual, se utiliza de fórmula retrógrada e inefetiva, incapaz de responder às problemáticas do mundo atual. ${ }^{3}$

familiar é a erosão da distinção entre combatentes e não-combatentes. As duas guerras mundiais da primeira metade do século envolveram toda a população dos países beligerantes; tanto combatentes quanto nāo-combatentes sofreram. De certo modo os efeitos da guerra na vida civil são ampliados pela globalizaçāo e pela crescente confiança do mundo em um fluxo constante, ininterrupto, de comunicações, serviços técnicos, entregas e suprimentos. (....) $O$ equilíbrio entre guerra e paz no século 21 não dependerá de arquitetar mecanismos mais eficientes para negociação e resolução, mas, sim, de estabilidade interna e de se conseguir que sejam evitados conflitos militares. Com poucas exceções, é menos provável que as rivalidades entre Estados que os levaram a conflitos armados no passado sejam capazes de fazê-lo hoje." Eric Hobsbawn, "A epidemia da guerra", Folha de S. Paulo, domingo, 14 de abril de 2002.

2. "This is not the brave new world order, or the creative resetting of debate, envisioned after II September. That day may not, it turns out, have prompted new thinking about world problems. It may have illuminated, more clearly than before, what kind of world we live in" Fred Halliday, "New world, but the saine old disorder". The Observer, Sunday, March 10, 2002.

3. Contra a idéia de um choque de civilizações, Edward Said é categórico ao firrmar: "For there are closer ties between apparently warring civilizations than most of us would like to believe; both Freud and Nietzsche showed how the traffic across carefully maintained, even policed boundaries moves with often terrifying ease. But then such fluid ideas, full of ambiguity and skepticism about notions that we hold on to, scarcely furnish us with suitable, practical guidelines for situations such as the one we face now. Hence the altogether more reassuring battle orders (a crusade, good versus evil, freedom against fear, etc.) drawn out of Huntington's alleged opposition between Islam and the West, from which official discourse drew its 
A partir desta breve introdução, gostaria de explorar os dois primeiros desafios, propostos por Fred Halliday, à luz de uma visão brasileira do Direito Internacional. Destacarei uma expressão chave para cada um dos dois desafios: do primeiro, segurança, do segundo, cooperação política.

O reforço da dimensão da segurança no âmbito internacional, eın era marcada pelo fluxo ininterrupto de pessoas, bens e informações, é impensável numa realidade política recortada em unidades soberanas autônomas se estas, por seu isolamento, possibilitarem ao infrator ausentar-se das sanções atribuídas pelas diversas legislações nacionais de cada Estado. A sanção, como instrumento de coerção que busca a revalidação do interesse do Estado em tutelar o direito, é imprescindível para imputar respeito à lei. A ineficácia normativa passa pelo sentimento de impunidade, algo que a cooperação judiciária internacional pode ajudar a sanar.

O respeito à lei nacional seria um importante avanço para enfrentar esta realidade cada vez mais anárquica, sedenta por certeza e segurança.

A cooperação judiciária entre as diferentes unidades políticas que se expressam no plano mundial é igualmente imprescindível para a eficácia da aplicação das respectivas legislações nacionais. A coordenação da cooperação internacional, se apenas diplomática, expressa-se de forma eminentemente descontínua, pois baseada apenas na arbitrariedade, autonomia política que reflete a extensão do conceito de soberania, é volúvel e incerta, dependendo dos interesses envolvidos caso a caso. No caso específico da extradição, o Brasil (art. 75, Lei n. 6.815 de 19 de agosto de 1980) somente a concede, na ausência de tratado, mediante declaração de reciprocidade do governo requerente. Porém, nem todos os países seguem esta linha, como o Reino Unido, que não observa o princípio da reciprocidade, não procedendo à extradição na ausência de tratado com o Estado requerente.

Resultado desta autonomia soberana dos Estados, a insegurança e arbitrariedade podem ser excluídas através da assinatura de tratados internacionais, pois, após a celebração do respectivo tratado internacional a intenção autônoma dos Estados signatários, se consolida em obrigação jurídica regulada pelo Direito Internacional. Esta é a grande importância dos tratados de cooperação judiciária; estabelecem, aos Estados, a obrigação de colaboração entre os judiciários na busca de levar a cabo a persecução judiciária, ou seja, a efetivação do direito.

Apenas a coordenação dos esforços dos Estados pode garantir a realização de um mundo dividido em unidades políticas soberanas, pois, se as fronteiras como expressão da soberania forem utilizadas como forma de evasão à lei, a própria legitimidade dos Estados estará comprometida, na medida em que a legitimidade

vocabulary in the first days after the September 11 attacks. There's since been a noticeable de-escalation in that discourse, but to judge from the steady amount of hate speech and actions, plus reports of law enforcement efforts directed against Arabs, Muslims and Indians all over the country, the paradigm stays on". Edward W. Said, The Clash of Ignorance, The Nation, 4/ $10 / 2001$. 
caminha de mãos dadas com a eficácia ${ }^{4}$ Tal argumento se faz cada vez mais presente em vista dos "novos perigos" que grassam pelo mundo globalizado de forma fluída, como o terrorismo, narcotráfico e crime organizado ${ }^{5}$ Assume, assim, a cooperação judiciária internacional, caráter de política de Estado, independendo da ideologia política professada pelos dirigentes estatais.

Não se trata, como parece a primeira vista, de uma mera colaboração; os tratados de cooperação judiciária são úteis como forma de redesenhar, num plano global, a soberania, já obsoleta se pensada classicamente como no século XIX. Porém, devemos destacar que a cooperação não é fenômeno novo, como fica patente no caso do Acordo para a Execução de Cartas Rogatórias firmado, em 1879, entre Brasil e Bolívia, ainda vigente. A cooperação passa, isto sim, a ganhar nova dimensão nas relações internacionais.

O campo da cooperação internacional jurisdicional se subdivide em três vertentes: competência internacional, reconhecimento e execução de sentenças

4. Na clássica lição de Miguel Reale: "O direito autêntico não é apenas declarado mas reconhecido, é vivido pela sociedade, como algo que se incorpora e se integra na sua maneira de conduzir-se. A regra de direito deve, por conseguinte, ser formalmente válida $e$ socialmente eficaz. (...) Para que se possa falar, por conseguinte, de "fonte de direito", isto é, de fonte de regras obrigatórias, dotadas de vigência e de eficácia, é preciso que haja um poder capaz de especificar o conteúdo do devido, para exigir o seu cumprimento, não sendo indispensável

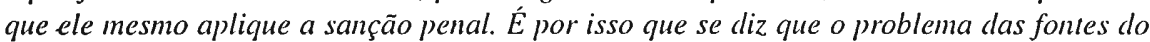
direito se confunde com o das formas de produção de regras de direito vigentes e eficazes, podendo ser elas genéricas ou não." Miguel Reale, Lições preliminares de direito, 24a. ed., São Paulo, Saraiva, 1998, p. 113 e 141.

5. Clara é a exposição de Fred Halliday, acerca deste novo momento: "(...) globalization is fostering a new politics. It creates the need for greater international co-operation - be it in constructing a 'financial architecture' to regulate the world economy, in intensified air traffic control requirements, in common taxation policies, or in regulating the environment. At the same time, the power of individual states is being eroded, and forms of international cooperation, between states, and transnational linkages, between social movements, NGOs and other elements of civil society, are growing, leading to use of the term 'global civil society' Easier travel and the possibilities of communication provided by the Internet allow not only' those with power but those without to communicate, mobilize and consult across frontiers and continents. In legal and ethical terms, the growth of international codes of rights and good practice, the challenging of state sovereignty through UN conventions on human rights and through various forms of humanitarian intervention suggest the possibility of a normative system that is, in aspiration and some degree in practice, international. Globalization, therefore, creates both the possibility and the need for international co-operation (....)." (....) criminals have been as quick as anyone else to take advantage of globalization and the reduction of state control of frontiers. In transnational relations, as within states, all that is non-state is not liberal: the Mafia, the drug traffickers, religious fundamentalists and anti-immigration groups could all claim to be part of global civil society. "Fred Halliday, Governance Beyond Frontiers, In: Fred Halliday, The World at 2000, Houndmills/Nova lorque, Palgrave, 2001, pp. 127 e 136. 
estrangeiras e tramitação internacional de atos processuais. O objetivo destas três vertentes cinge-se, respectivamente, à regulação dos conflitos internacionais de jurisdição, à determinação das condições para o reconhecimento e execução de atos decisórios de caráter constritivo - sejam condenatórios, sejam constitutivos, emanados por autoridade estrangeira no exercício da função jurisdicional -, e à realização, em uma jurisdição, de atos processuais no interesse de outra jurisdição.

Na cooperação entre Estados em matéria penal, segundo Nadia de Araújo, podemos subdividi-la em três ramos: primeiro, o ramo que diz respeito à colaboração no cumprimento de atos instrutórios e cautelares necessários ao desenvolvimento de determinado processo penal; segundo, o que tange à colaboração na localização, detenção e devolução do acusado da prática de determinado delito, ou daquele que já considerado culpado da prática do mesmo, para que responda a processo ou que cumpra a respectiva sanção penal - o que se dá através da extradição; e o terceiro, o que cuida da colaboração na produção de efeitos, no território de um Estado, originários de uma sentença penal condenatória, havida em outro Estado.

Tratando da extradição, o primeiro passo seria defini-la, distinguindo-a da expulsão e do banimento. Na lição de G. E. do Nascimento e Silva e Hildebrando Accioly: "a extradição é o ato mediante o qual um Estado entrega a outro indivíduo acusado de haver cometido crime de certa gravidade ou que já se ache condenado por aquele, após haver-se certificado de que os direitos humanos do extraditando serão garantidos. A instituição da extradição tem por objetivo principal evitar, mediante a cooperação internacional, que um individuo deixe de pagar pelas consequências de crime cometido" Já Celso D. de Albuquerque Mello: "A extradição pode ser definida como sendo o ato por meio do qual o indivíduo é entregue por um Estado a outro, que seja competente a fim de processá-lo e puni-lo" ". A primeira definição menciona restrições humanitárias à extradição, constantes do Direito Internacional e previstas na legislação pátria.

Essas restrições à concessão da extradição de caráter humanitário são: i). impossibilidade de pena de morte ou corporal; ii). impossibilidade de ter o inculpado que responder perante tribunal de exceção.

A Convenção Americana sobre Direitos Humanos (art. $\left.5^{\circ} \S 2\right)$ e o Pacto Internacional de Direitos Civis e Políticos (art. $7^{\circ}$ ) são claros na proibição da tortura. Tortura compreendida tal como estipula o art. $1^{\circ}$ da Convenção contra a tortura e outros tratamentos ou penas cruéis, desumanos ou degradantes define, ou seja, como “(....) qualquer ato pelo qual dores ou sofrimentos agudos físicos ou mentais, são infligidos intencionalmente a uma pessoa a fim de obter desta ou de terceira pessoa, informações ou confissões; de castigá-la por ato que esta ou uma terceira pessoa tenha cometido ou sejam suspeitas de ter cometido; de intimidar ou coagir esta pessoa ou outras

6. Hildebrando Accioly, Manual de direito internacional público/ Hildebrando Accioly, G. E. do Nascimento e Silva, 14a ed. São Paulo, Saraiva, 2000, p. 364.

7. Celso D. de Albuquerque Mello, Direito Constitucional Internacional, Rio de Janeiro, Renovar, 1994, p. 169. 
pessoas; ou por qualquer motivo baseado em discriminação de qualquer natureza; quando tais dores ou sofrimentos são infligidos por um funcionário público, ou por sua instigação, ou com o seu consentimento ou aquiescência. Não se considerará como torturas as dores ou sofrimentos que sejam conseqüência unicamente de sanções legítimas, ou que sejam inerentes a tais sanções ou delas decorrem."

A Convenção Interamericana para Prevenir e Punir a Tortura, concluída em 1985, estipula que deve se incluir nos Tratados de extradição a tortura como crime extraditável. Sendo a tortura proibida mesmo em Estado de guerra, estado de sítio, conflitos internos e demais convulsões sociais. A tortura, segundo muitos, é atualmente norma de "jus cogens" do DIP, ou seja, que somente passível de derrogação pela sociedade internacional como um todo. A Constituição Federal de 1988, em seu art. $5^{\circ}$. XLVII, $a$, $e, \mathrm{XLIX}$, prescreve a garantia de respeito aos direitos humanos. Segundo estas disposições, a condenação à pena de morte é incompatível com o direito pátrio, sendo somente concedida a extradição se comutada a pena em pena de prisão. Seguindo esta orientação, já fïrmada há muito no direito pátrio, o Tratado de Extradição entre o Brasil e o México, de 1933, em seu art. VIII, declarada a impossibilidade da extradição no caso de pena de morte ou corporal. Mesma disposição consta do Tratado de Extradição entre o Brasil e o EUA, em seu art. $6^{\circ}$ (esta cláusula é uma constante nos tratados de extradição firmados pelo Brasil, os exemplos citados têm caráter meramente exemplificativo).

Paradigmático é o acórdão referente à extradição n. 633 - República da China, Relator: Min. Celso de Mello, em que o Governo chinês requeria a extradição de um estelionatário, crime este punido com pena capital naquela Nação. O pedido foi indeferido pelo STF, com base no binômio respeito aos direitos humanos-garantia do devido processo legal (due process of law).

A garantia do devido processo legal expressa na Constituição Federal de 1988 (art. 5, LIV) se esteia também no art. XI da Declaração Universal dos Direitos do Homem, que visa garantir ao acusado um julgamento justo, em que sejam observadas as garantias à defesa, dentro da presunção de inocência e do respeito ao princípio da legalidade. Dispositivos que vinculam a extradição à garantia do devido processo legal, constam expressamente de diversos tratados de extradição firmados pelo Brasil. Dentre eles, o celebrado com o Peru, que em seu art. I, 5, declara estarem as partes obrigadas à extraditar quando “ (....) o inculpado não tenha de responder no país requerente, perante algum tribunal ou juízo de exceção." $"$

Dentre as exceções à extradição, figuram outras, que não as humanitárias, como a impossibilidade nos casos de crime político, de opinião, militar e religioso. A

8. Atualmente muito em voga, após os atentados terroristas de 11 de setembro de 2001 , o esforço realizado para identificar e prender supostos terroristas teria grandes obstáculos. Ocorrendo a prisão de inculpado de terrorismo em território brasileiro, o pedido de extradição, se requerido pelos EUA, seria prejudicado, pois o julgamento do inculpado se realizaria em tribunal de exceção, de caráter militar, sob a "justificativa" de estado de guerra, conforme as últimas medidas toscamente adotadas pelo Governo norte-americano, o que configuraria causa impeditiva da aludida extradição. 
Constituição, em seu art. $5^{\circ}$. LII, declara que " não será concedida extradição de estrangeiro por crime político ou de opinião "

Dentre essas hipóteses, de grande dificuldade é a de crime político, devido a sua amplitude e vagueza. Celso D. de Albuquerque Mello apresenta três critérios para a caracterização do crime político: "i). objetivista - define o crime político como sendo aquele perpetrado contra a ordem política estatal; o importante é que o bem jurídico atingido seja de natureza política; ii). subjetivista-considera crime político o que foi cometido com a finalidade política; iii). o mais adotado atualmente é o critério misto resultante da combinação dos dois critérios anteriores. Entretanto, não há nenhuma obrigatoriedade para o Estado de adotar este ou aquele critério." "

Os atentados contra chefe de Estado ou sua família não são considerados crimes políticos. Os atos terroristas também não são considerados políticos, sendo passíveis de extradição, apesar de visarem sempre objetivos políticos. Porém, os atos terroristas são considerados crimes comuns, no sentido de ter obrigatoriedade jurídica aos Estados que ratificam tratados de extradição, já aos demais são livres para qualificálos como políticos ou comuns.

Muitos são os que se colocam contrários a exclusão dos crimes políticos do rol dos crimes passíveis de extradição, por considerarem que, apesar de políticos, podem causar as mais graves conseqüências.

A doutrina enumera também, como excludente à extradição, a inviolabilidade absoluta de chefes de Estado; porém casos recentes como o do general Augusto Pinochet e a criação do Tribunal Penal Internacional da Haia para julgamento por crime cometidos na Iugoslávia, com o indiciamento do presidente Slobodan Milosevic, enfraqueceram a invocação desta excludente.

Outra impossibilidade é a extradição do nacional ou nacionalizado. Essa posição é adotada pela maioria das nações. É expressa a Constituição Federal de 1988 , à esse respeito: " nenhum brasileiro será extraditado, salvo o naturalizado, em caso de crime comum, praticado antes da naturalização, ou de comprovação envolvimento em tráfico ilícito de entorpecentes e drogas afins, na forma da lei" (art. $5^{\circ}$., LI ).

Preponderantemente questão concernente às relações internacionais, o pedido para a extradição deve ser processado através da via diplomática. No caso brasileiro, todo pedido deve ser encaminhado ao ministério das Relações Exteriores que o repassa ao STF, a fim de que as exigências formais e humanitárias sejam aptas para a concessão do pedido.

Conclusão.

Nesta breve incursão, gostaríamos de pontuar a relevância da cooperação judiciária internacional como instrumento apto a dar conta das circunstâncias difusas

9. Celso D. de Albuquerque Mello, Direito Constitucional Internacional, Rio de Janeiro, Renovar, 1994, p. 170. 
de um mundo cada vez mais permeado pela crescente circulação de bens, informações e pessoas. Atualmente, a fragmentação política (o mundo continua dividido em Estados soberanos e isto não tende a mudar à curto prazo, já que o Estado continua a ser a única instância de regulação social, bem como de exercício da cidadania), a par do encurtamento de tempo e distâncias proporcionados pelo incrível desenvolvimento dos transportes e comunicações, colocam em xeque a atuação de um Estado isolado, se pensado como unidade autárquica.

Os atentados terroristas de 11 e setembro de 2001 contra o Pentágono e o WTC desnudaram as complexidades trazidas pela crescente interdependência entre os Estados, e das quais não se aproveitam apenas o sistema financeiro, tantas vezes apontado como vilão da globalização e desestabilizador de economias nacionais, mas também as organizações terroristas, a máfia, os traficantes de drogas e outros agentes violadores da lei e da ordem. Nesse diapasão, notamos a necessidade de reforçar a esfera de segurança, através da cooperação política entre os Estados. Nessas circunstâncias, a cooperação judiciária internacional, como instrumento jurídico capaz de promover a cooperação em bases seguras e estáveis, destaca-se e se constitui numa importante ferramenta, da qual os Estados podem se utilizar para enfrentar os "novos perigos" do atual contexto mundial.

Novo contexto, que exige adaptação do Direito a esses novos paradigmas de ação internacional, reformulando essencialmente a natureza e limites da ação estatal, destituída de sua anterior importância e alcance, impotente diante de outras instituições e agentes "mais ágeis"

A par desta realidade duas lições resumem de forma sucinta a necessidade da já demasiadamente citada cooperação internacional jurisdicional. A primeira, ensinada por Georges Ripert, "quando o direito ignora a realidade, a realidade se vinga, ignorando o direito" a segunda, não menos importante, citada por Hans Morgenthau, "a ética na política é a prudência" Neste caso, é imperiosa, para o estabelecimento de ordem internacional segura e estável, a sensibilidade dos policymakers em compreender a importância da cooperação judiciária em âmbito internacional, sob pena de formularem política ineficazes e, portanto, imprudentes.

São Paulo, janeiro de 2002.

Anexos.

Tratados de Cooperação judiciária firmados pelo Brasil e vigentes.

\section{Acordos bilaterais}

\section{Alemanha}

1.1 Acordo de Garantia de Reciprocidade na Transmissão do Registro Penal. Assinado em Bonn, em 15/05/1957. Concluído por troca de notas (nota alemã n. 503, de 01/04/1957 e nota brasileira de 15/05/1957). 


\section{Argentina}

2.1 Convenção sobre Assistência Judiciária Gratuita. Assinada em Buenos Aires, em 15/11/1961. Aprovado por meio do Decreto Legislativo n. 53 de 31/08/1964. Promulgado por meio do Decreto n. 62.978, de 11/07/1968.

2.2 Acordo de Cooperação Judiciária em Matéria Civil, Comercial, Trabalhista e Administrativa. Assinado em Brasília, em 20/08/1991. Aprovado por meio do Decreto Legislativo n. 47, de 10/04/1995. Promulgado por meio do Decreto n. 1.560, de 18/07/1995.

2.3 Tratado sobre Transferência de Presos. Assinado em Buenos Aires, em 11/ 09/1998. Aprovado por meio do Decreto Legislativo n. 6, de 25/01/1999. Promulgado por meio do Decreto n. 3.875, de 23/07/2001.

\section{Bélgica}

3.I Convenção sobre Assistência Judiciária Gratuita. Assinada no Rio de Janeiró, em 10/01/1955. Aprovado por meio do Decreto Legislativo n. 1, de 07/02/1957. Promulgado por meio do Decreto n. 41.908, de 29/07/1957.

\section{Bolivia}

4.1 Acordo para a Execução de Cartas Rogatórias. Assinado em La Paz, em 22/ 12/1879. Promulgado por meio do Decreto n. 7.857, de 15/10/1880.

\section{Canadá}

5.1 Tratado sobre Transferência de Presos. Assinado em Brasília, em 15/07/ 1992. Aprovado por meio do Decreto Legislativo n. 22, de 24/08/1993. Promulgado por meio do Decreto n. 2.547, de 14/04/1998.

\section{Chile}

6. I Acordo sobre Cartas Rogatórias. Assinado em Santiago do Chile, em 10/02/ 1970. Concluído por troca de notas (nota chilena n. 841 e nota brasileira n. 24 de 10/02/ 1970).

6.2 Tratado sobre Transferência de Presos Condenados. Assinado em Brasília, em 29/04/1998. Aprovado por meio do Decreto Legislativo n. 5, de 25/01/1999. Promulgado por meio do Decreto n. 3.002, de 26/03/1999.

\section{Colômbia}

7.1 Acordo de Cooperação Judiciária e Assistência Mútua em Matéria Penal. Assinado em Cartagena das Índias, em 07/11/1997. Aprovado por meio do Decreto Legislativo n. 4 I de 18/06/1999. Promulgado por meio do Decreto n. 3895, de 23/08/ 2001 .

\section{Espanha}

8.1 Convênio de Cooperação Judiciária em Matéria Civil. Assinado em Madri, em 13/04/1989. Aprovado por meio do Decreto Legislativo n. 31, de 16/10/1990. Promulgado por meio do Decreto n. 166 de 03/07/1991.

8.2 Tratado sobre Transferência de Presos. Assinado em Brasília, em 07/11/ 
1996. Aprovado por meio do Decreto Legislativo n. 58, de 28/10/1997. Promulgado por meio do Decreto n. 2.576, de 30/04/1998.

\section{Estados Unidos da América}

9.1 Acordo de Assistência Judiciária em Matéria Penal. Assinado em Brasília, em 14/10/1997. Aprovado por meio do Decreto Legislativo n. 262, de 18/12/2000. Promulgado por meio do Decreto n. 3.810, de 2/05/2001.

\section{França}

10.1 Acordo de Cooperação Judiciária em Matéria Penal. Assinado em Paris, em 28/05/1996. Aprovado por meio do Decreto Legislativo n. 74, de 03/09/1999. Promulgado por meio do Decreto n. 3.324, de 30/12/1999.

10.2 Acordo de Cooperação Judiciária em Matéria Civil. Assinado em Paris, em 28/05/1996. Aprovado por meio do Decreto Legislativo n. 163, de 03/08/2000. Promulgado por meio do Decreto n. 3.598, de 12/09/2000.

10.3 Acordo, por troca de Notas, sobre a Gratuidade Parcial da Execução das Cartas Rogatórias em Matéria Penal. Aprovado pelo Decreto Legislativo n. 100, de I6/ 04/1991. Promulgado pelo Decreto n. 585, de 26/06/1992.

\section{Itália}

11.1 Tratado sobre Cooperação Judiciária em Matéria Penal. Assinado em Roma, em 17/10/1989. Aprovado por meio de Decreto Legislativo n. 78, de 20/11/1992. Promulgado por meio do Decreto n. 862, de 09/07/1993.

11.2 Tratado Relativo à Cooperação Judiciária e ao Reconhecimento e Execução de Sentenças em Matéria Civil. Assinado em Roma, em 17/10/1989. Aprovado por meio de Decreto Legislativo n. 78, de 20/11/1992. Promulgado por meio do Decreto n. 1.476, de 02/05/1995.

\section{México}

12.1 Acordo de Isenção de Legalização Consular. Assinado na Cidade do México, em 26/11/1970. Concluído por troca de notas (nota brasileira n. 190 de 26/11/ 1970 e nota mexicana n. 512.112, de 26/11/1970).

\section{Países baixos}

13.1 Convenção sobre Assistência Judiciária Gratuita. Assinada no Rio de Janeiro em 16/03/1959. Aprovada por meio do Decreto Legislativo n. 23, de 23/10/1963. Promulgada por meio do Decreto n. 53.923, de 20/05/1964.

13.2 Acordo para a Extensão ao Suriname e às Antilhas Neerlandesas da Convenção sobre Assistência Judiciária Gratuita de 1959. Assinado no Rio de Janeiro, em 16/11/1964. Entrada em vigor em 16/11/1964. Concluído por troca de notas (nota Neerlandesa de 09/10/1964; nota brasileira de 16/11/1964.

\section{Paraguai}

14.I Acordo para Restituição de Veículos Automotores Roubados e Furtados. 
Assinado em Brasília, em 01/09/1994. Aprovado por meio do Decreto Legislativo n. 139, de 29/11/1995. Promulgado por meio do Decreto n. 2.131, de 20/01/1997.

15. Peru

15.1 Acordo de Assistência Jurídica em Matéria Penal. Assinado em Lima em 21/07/1999. Decreto Legislativo n. 181, de 07/06/2001.

\section{Portugal}

16.1 Tratado de Auxílio Mútuo em Matéria Penal. Assinado em Brasília, em 07/05/1991. Aprovado por meio do Decreto Legislativo n. 77, de 19/11/1992. Promulgado por meio do Decreto n. 1.320, de 30/11/1994.

16.2 Tratado de Amizade, Cooperação e Consulta. Assinado em Porto Seguro, em 22/04/2000. Aprovado por meio do Decreto Legislativo n. 165, de 30/05/2001. Promulgado por meio do Decreto n. 3.927, de 19/09/2001.

\section{Suiça}

17. I Acordo para a Dispensa da Legalização Consular. Assinado em Brasília, em 14/10/1970. Concluído por troca de notas (nota brasileira $n .^{\circ}$ (DAI/DJ/DCn/65/ 021 (89) de 17/09/1970 e nota suíça n. 45.410, de 14/10/1970).

\section{Uruguai}

18.1 Acordo de Cooperação Judiciária em Matéria Civil, Comercial, Trabalhista e Administrativa. Assinado em Montevidéu, em 28/12/1992. Aprovado por meio do Decreto Legislativo n. 77, de 09/05/1995. Promulgado por meio do Decreto n. 1850 de 10/04/1996.

\section{Acordos Regionais e Acordos Multilaterais}

1. Ilanud (Instituto Latino-anericano das Nações Unidas para a Prevenção do Crime e o Tratamento do Criminoso)

1.l Acordo de Cooperação para a Prevenção do Crime e o Tratamento do Criminoso. Assinado em São José da Costa Rica, em 30/1 1/1989. Aprovado por meio do Decreto Legislativo n. 115, de 03/12/1996. Promulgado por meio do Decreto n. 2151 de 19/02/1997.

\section{Mercosul}

2.1 Protocolo de Cooperação e Assistência Jurisdicional em Matéria Civil, Comercial, Trabalhista e Administrativa, concluído pelos governos da Argentina, do Brasil, do Paraguai e do Uruguai. Assinado em Lãs Leñas, em 27/06/1992. Aprovado por meio do Decreto Legislativo n. 55, de 19/04/1995. Decreto n. 2.067, de 12/11/1996.

2.2 Protocolo de Medidas Cautelares, concluído pelos governos da Argentina, do Brasil, do Paraguai e do Uruguai. Assinado em Ouro Preto, em 16/12/1994. Entrada em vigor em 18/04/1997. Aprovado por meio do Decreto Legislativo n. 192, de 15/12/ 1995. Promulgado por meio do Decreto n. 2.626, de 15/06/1998. 
2.3 Protocolo de Assistência Jurídica Mútua em Assuntos Penais, concluído pelos governos da Argentina, do Brasil, do Paraguai e do Uruguai. Assinado em San Luis, República Argentina, em 25/06/1996. Aprovado por meio do Decreto Legislativo n. 03, de 26/01/2000. Promulgado por meio do Decreto n. 3.468, de 17/05/2000.

2.4 Protocolo de São Luiz sobre Matéria de Responsabilidade Civil Emergente de Acidentes de Trânsito entre os Estados Partes do Mercosul. Assinado em San Luis, República Argentina, em 25/06/1996, e a respectiva Errata, feita em Assunção, em I9/ 06/1997. Aprovado por meio do Decreto Legislativo n. 259, de 15/12/2000. Promulgado por meio do Decreto n. 3.856, de 03/07/2001.

\section{Organização dos Estados Americanos}

3.1 Convenção Interamericana sobre Cartas Rogatórias, em matéria civil ou comercial. Assinada no Panamá, em 30/01/1975. São partes da referida Convenção os seguintes países: Chile, Equador, Estados Unidos, Guatemala, México, Panamá, Paraguai, Peru, Uruguai e Venezuela. Aprovada por meio do Decreto Legislativo $n$. 61, de 19/04/1995. Promulgada por meio do Decreto n. 1.899; de 09/05/1996.

3.2 Convenção Interamericana sobre Regime Legal das Procurações para serem Utilizadas no Exterior. Assinada na cidade do Panamá, em 30/01/1975. Aprovada por meio do Decreto Legislativo n. 4, de 7/02/1994. Promulgada por meio do Decreto $\mathrm{n}$. 1.213 , de 03/08/1994.

3.3 Convenção Interamericana sobre Prova e Informação Acerca do Direito Estrangeiro. Assinada em Montevidéu, em 08/05/1979. Aprovada por meio do Decreto Legislativo n. 46, de 10/04/1995. Promulgada por meio do Decreto n. 1.925, de 10/06/ 1996.

3.4 Protocolo Adicional à Convenção Interamericana sobre Cartas Rogatórias, em matéria civil ou comercial. Assinado em Montevidéu, em 08/05/1979. Aprovado por meio do Decreto Legislativo n. 61, de 19/04/1995. Decreto n. 2.022, de 07/10/ 1996.

3.5 Convenção Interamericana sobre Eficácia Extraterritorial das Sentenças e Laudos Arbitrais Estrangeiros, proferidos em processos civis, comerciais ou trabalhistas. Assinada em Montevidéu, em 08/05/1979. Aprovado por meio do Decreto Legislativo n. 93, de 20/06/1995. Promulgada por meio do Decreto n. 2.411, de 02/12/1997.

3.6 Convenção Interamericana sobre Obrigação Alimentar (IV CIDIP). Assinada em Montevidéu, em 15/07/1989. . Aprovada por meio do Decreto Legislativo n. 1, de 28/02/1996. Promulgada por meio do Decreto n. 2.428, de 17/12/1997.

3.7 Convenção Interamericana sobre Tráfico Internacional de Menores. Assinada na Cidade do México, em 18/03/1994. Aprovada por meio do Decreto Legislativo n. 105, de 30/10/1996. Promulgada por meio do Decreto n. 2.740, de 20/08/1998.

\section{Convenção de Nova Iorque}

4.1 Convenção sobre Prestação de Alimentos no Estrangeiro. São partes da referida Convenção os seguintes países: Alemanha, Alto Volta, Argélia, Argentina, 
Áustria, Bélgica, Bolívia, Camboja, Ceilão, Chile, China, Colômbia, Cuba, Dinamarca, El Salvador, Equador, Espanha, Filipinas, Finlândia, França, Grécia, Guatemala, Haiti, Hungria, Israel, lugoslávia, Luxemburgo, Marrocos, México, Mônaco, Niger, Noruega e Países Baixos.

Assinada em 31/121956. Aprovada por meio do Decreto Legislativo n. 10, de 13/1 1/1958. Promulgada por meio do Decreto n. 56.826, de 02/09/1965.

5. Convenção sobre o Combate da Corrupção de Funcionários Públicos Estrangeiros em Transações Comerciais Internacionais

5.1 Convenção sobre o Combate da Corrupção de Funcionários Públicos Estrangeiros em Transações Comerciais Internacionais. Assinada em Paris, em 17/12/ 1997. Aprovada por meio do Decreto Legislativo n. I25, de 14/06/2000. Promulgada por meio do Decreto n. 3.678, de 30/11/2000.

6. Convenção sobre os Aspectos Civis do Seqüestro Internacional de Crianças

6.1 Convenção sobre os Aspectos Civis do Seqüestro Internacional de Crianças. Assinada em Haia, em 25/10/1980 (com reserva ao art. 24 da Convenção, permitida pelo seu art. 42, para determinar que os documentos estrangeiros juntados aos autos judiciais sejam acompanhados de tradução para o português, feita por tradutor juramentado oficial). Aprovada por meio do Decreto Legislativo n. 79, de 15/09/1999. Promulgada por meio do Decreto n. 3.413, de 14/04/2000.

7. Convenção Relativa à Proteção das Crianças e à Cooperação em Matéria de Adoção Internacional

7.1 Convenção relativa à Proteção das Crianças e à Cooperação em matéria de Adoção. Assinada em Haia em 29/05/1993. Aprovada por meio do Decreto Legislativo n. 1, de 14/01/1999. Promulgada por meio do Decreto n. 3.087, de 21/06/1999.

\section{Extradição}

\section{Acordos Bilaterais}

\section{Argentina}

1.I Tratado de extradição. Assinado em Buenos Aires, em 15/I I/1961. Aprovado por meio do Decreto Legislativo n. 85, de 29/09/1964. Promulgado por meio do Decreto n. 62.979 , de 11/07/1968.

\section{Austrália}

2.1 Tratado sobre Extradição. Assinado em Camberra, em 22/08/1994. Aprovado por meio do Decreto Legislativo n. 36, de 28/03/1996. Promulgado por meio do Decreto n. 2.010, de 23/09/1996.

\section{Bélgica}

3.1 Tratado de Extradição. Assinado no Rio de Janeiro, em 06/05/1953. Aprovado pelo Decreto Legislativo n. 26, de 19/06/1956. Promulgado por meio do Decreto n. 41.909, de 29/07/1957. 


\section{Bolívia}

4.1 Tratado de Extradição. Assinado no Rio de Janeiro, em 25/02/1938. Aprovado por meio do Decreto Lei n. 345 , de 22/03/1938. Promulgado por meio do Decreto n. 9.920, de 08/07/1942.

\section{Chile}

5.1 Tratado de Extradição. Assinado no Rio de Janeiro, em 08/09/1935.Aprovado por meio do Decreto Legislativo n. 17, de 01/08/1936. Promulgado por meio do Decreto n. 1.888 , de 17/08/1937.

\section{Colômbia}

6.1 Tratado de Extradição. Assinado no Rio de Janeiro, em 28/12/1938. Aprovado por meio do Decreto Lei n. 1994 de 31/01/1940. Promulgado por meio do Decreto n. 6.330 de 25/09/1940.

\section{Coréia do Sul}

7.1 Tratado de extradição. Assinado em Brasília, em 01/09/1995. Aprovado por meio do Decreto Legislativo n. 263, de 28/12/2000. Promulgado por meio do Decreto n. 4.152 , de 7/03/2002. Considerando que a ressalva introduzida à versão em idioma português do tratado pelo referido decreto legislativo, ressalva esta objeto de acordo, por troca de notas, entre os dois governos, de 18 de dezembro de 2001 , se acha devidamente incorporada ao texto do tratado promulgado.

\section{Equador}

8.1 Tratado de Extradição. Assinado no Rio de Janeiro, em 04/03/1937. Aprovado por meio do Decreto Legislativo n. 110, de 24/09/1937. Promulgado por meio do Decreto n. 2.950, de 08/08/1938.

\section{Espanha}

9.1 Tratado de Extradição. Assinado em Brasília, em 02/02/1988. Aprovado por meio do Decreto Legislativo n. 75, de 29/11/1989. Decreto n. 99.340, de 22/06/ 1990.

\section{Estados Unidos da América}

10.1 Tratado de Extradição. Assinado no Rio de Janeiro, em 13/01/1961. Aprovado por meio do Decreto Legislativo n. 13, de 18/06/1964. Promulgado por meio do Decreto n. 55.750, de 11/02/1965.

10.2 Protocolo Adicional ao Tratado de Extradição. Assinado no Rio de Janeiro, em 18/06/1962. Aprovado por meio do Decreto Legislativo n. 13, de 18/06/1964. Promulgado por meio do Decreto n. 55.750, de 11/02/1965.

\section{Itália}

11.1 Tratado de Extradição. Assinado em Roma, em 17/10/1989. Aprovado por meio do Decreto Legislativo n. 78, de 20/11/1992. Promulgado por meio do Decreto n. 863, de 09/07/1993. 


\section{Lituânia}

12.1 Tratado de Extradição. Assinado no Rio de Janeiro, em 28/09/1937. Aprovado por meio do Decreto Lei n. 950, de 13/12/1938. Promulgado por meio do Decreto n. 4528, de 16/08/1939.

\section{México}

13.1 Tratado de Extradição. Assinado no Rio de Janeiro, em 28/12/1933. Aprovado por meio do Decreto Lei n. 28, de 30/1//1937. Promulgado por meio do Decreto n. 2.535, de 22/03/1938.

13.2 Protocolo Adicional ao Tratado de Extradição. Assinado no Rio de Janeiro, em 18/09/1935. Aprovado por meio do Decreto Lei n. 28, de 30/11/1937. Promulgado por meio do Decreto n. 2.535, de 22/03/1938.

\section{Paraguai}

14.1 Tratado de Extradição. Assinado em Assunção, em 24/02/1922. Aprovado por meio do Decreto Legislativo n. 4612, de 29/11/1922. Promulgado por meio do Decreto n. 16.925, de 27/05/1925.

\section{Peru}

15.1 Tratado de Extradição. Assinado no Rio de Janeiro, em 13/02/1919. Aprovado por meio do Decreto n. 4236, de 04/01/1921. Promulgado por meio do Decreto n. 15.506, de 31/05/1922.

\section{Portugal}

16.1 Tratado de Extradição. Assinado em Brasília, em 07/05/1991. Aprovado por meio do Decreto Legislativo n. 96, de 23/12/1992. Promulgado por meio do Decreto n. 1.325, de 02/12/1994.

\section{Reino Unido}

17.1 Tratado de Extradição. Assinado em Londres, em 18/07/1995. Aprovado por meio do Decreto Legislativo n. 91, de 1//09/1996. Promulgado por meio do Decreto n. 2.347, de 10/10/1997.

\section{Suiça}

18. I Tratado de Extradição. Assinado no Rio de Janeiro, em 23/07/1932. Promulgado por meio do Decreto n. 23.997, de 13/03/1934.

19. Uruguai

19.1 Tratado de Extradição. Assinado no Rio de Janeiro, em 27/12/1916. Aprovado por meio do Decreto Legislativo n. 3607, de 13/12/1918.

Promulgado por meio do Decreto n. 13.414, de 15/01/1919.

19.2 Protocolo Adicional ao Tratado de Execução. Assinado no Rio de Janeiro, em 07/12/1921. Aprovado por meio do Decreto Legislativo n. 4539, de 04/02/ 1922. Promulgado por meio do Decreto n. 17.572, de 30/11/1926.

20. Venezuela

20.1 Tratado de Extradição. Assinado no Rio de Janeiro, em 07/12/1938. Aprovado por meio do Decreto Lei n. 4.868, de 09/1 1/1939. Promulgado por meio do Decreto n. 5.362, de 12/03/1940. 